\title{
Role of cytokines and chemokines in alcohol- induced tumor promotion
}

This article was published in the following Dove Press journal:

OncoTargets and Therapy

17 March 2017

Number of times this article has been viewed

\section{Danlei Chen' \\ Fengyun Zhang' \\ Haifeng Ren' \\ Jia Luo ${ }^{2}$ \\ Siying Wang'}

'School of Basic Medical Sciences, Anhui Medical University, Hefei, Anhui, People's Republic of China; 2Department of Pharmacology and Nutritional Sciences, University of Kentucky, College of Medicine, Lexington, KY, USA
Correspondence: Siying Wang School of Basic Medical Sciences, Anhui Medical University, 8I Meishan Road, Hefei 230032, Anhui, People's Republic of China

$\mathrm{Tel} / \mathrm{fax}+866516 \quad 1215$

Email sywang@ahmu.edu.cn

\begin{abstract}
Excessive chronic alcohol consumption has become a worldwide health problem. The oncogenic effect of chronic alcohol consumption is one of the leading concerns. The mechanisms of alcohol-induced tumorigenesis and tumor progression are largely unknown, although many factors have been implicated in the process. This review discusses the recent progress in this research area with concentration on alcohol-induced dysregulation of cytokines and chemokines. Based on the available evidence, we propose that alcohol promotes tumor progression by the dysregulation of the cytokine/chemokine system. In addition, we discuss specific transcription factors and signaling pathways that are involved in the action of these cytokines/chemokines and the oncogenic effect of alcohol. This review provides novel insight into the mechanisms of alcohol-induced tumor promotion.
\end{abstract}

Keywords: alcohol, tumor promotion, cytokines, chemokines, transcription factors, signal transduction, therapy

\section{Introduction}

Alcohol is a tumor promoter. ${ }^{1}$ Alcohol is involved in tumor promotion by not only alcohol itself but also the derivatives of alcohol, such as acetaldehyde and free radicals that are generated in the metabolic process. For example, acetaldehyde, proteins, and DNA may form adduct, which leads to genetic mutations that induce tumorigenesis. Alcohol abuse is defined as intake of alcohol that exceeds 21 units weekly or 3 units per day. Alcohol abuse is a major risk factor for tumors, especially the upper gastrointestinal tract (oral cavity, pharynx, larynx, and esophagus) tumors, hepatocellular carcinoma (HCC), colorectal cancer, and breast cancer. ${ }^{2-6}$ Furthermore, in many types of tumors, including gastrointestinal tract, gynecological, brain, and renal tumors, the activity of alcohol dehydrogenase is significantly increased. ${ }^{7}$

Alcohol exposure also enhances the progression and metastasis of a variety of tumors, such as skin, liver, lung, breast, and colon cancers. ${ }^{8-13}$ Chronic alcohol consumption is often associated with poor clinical prognosis. ${ }^{9}$ However, the underlying cellular and molecular mechanisms are complex.

Alcohol consumption is one of the risk factors that correlate with high cancer mortality rates, ${ }^{14}$ and this is mainly because chronic alcohol consumption often leads to advanced TNM stages, greater vessel invasion, and poorer prognosis. ${ }^{9}$ The underlying mechanism may be that alcohol consumption activates the expression of some cytokines, such as VEGF, MCP-1, and NF- $\kappa \mathrm{B}$, which are associated with tumor progression and metastasis. ${ }^{8-10}$

This review discusses the current research progress in the cellular and molecular mechanisms underlying alcohol-induced tumor promotion. We specifically focus on 
the role of cytokines and chemokines in alcohol-promoted tumor progression and aggressiveness.

\section{Alcohol-induced dysregulation of cytokines and chemokines}

Cytokines are small molecule proteins with a broad range of biological activities. They are normally synthesized and secreted by the immune cells, such as monocytes, macrophages, T cells, B cells, and natural killer cells, as well as some nonimmune cells, such as endothelial cells and fibroblasts. Cytokines regulate cell growth and differentiation by binding to the specific receptors and mediate the immune response. ${ }^{15,16}$ Chemokines are chemotactic cytokines that mediate the migration and positioning of the target cells. ${ }^{17}$ In addition to mediating immune response, chemokines are also involved in regulating the embryonic development, angiogenesis, and apoptosis. More importantly, chemokines are now known to play a vital role in tumorigenesis, tumor progression, and metastasis. ${ }^{18,19}$ The most well-investigated cytokines and chemokines include VEGF, MCP-1, TLR, and TNF- $\alpha$. Alcohol exposure affects the cytokine and chemokine systems. ${ }^{20-22}$ Particularly, the effects of alcohol on VEGF and MCP-1 receive great attention due to their roles in tumorigenesis and progression.

\section{VEGF}

VEGF is a highly conservative glycoprotein ${ }^{23,24}$ and plays an important role in angiogenesis, invasion of tumors, ${ }^{25,26}$ cell proliferation, and vascular permeability. ${ }^{27-29}$ VEGF is significantly upregulated in tumor tissues and positively correlated with malignancy. ${ }^{30,31}$ It is proposed that alcohol promotes tumor growth, angiogenesis, and metastasis in skin cancer, liver cancer, and breast cancer by increasing the VEGF levels. ${ }^{8,32}$ In addition, oxidative stress and NF- $\kappa \mathrm{B}$ mediate the alcohol-induced VEGF upregulation. ${ }^{9}$ However, the exact signaling mechanisms are still largely unknown.

\section{MCP-I}

MCP-1, also called CCL2, activates the mononuclear cells and macrophages by increasing the intracytoplasmic $\mathrm{Ca}^{2+}$ concentration and releasing the superoxide anion and lysozyme. ${ }^{33}$ Moreover, many studies also demonstrated that MCP-1 plays essential roles in tumor microenvironment by regulating tumor angiogenesis, tumor growth, and metastasis. ${ }^{34-36}$ Alcohol exposure upregulates MCP-1 and recruits M2 macrophages in tumor microenvironment, which, in turn, promotes the growth and metastasis of lung cancer (Figure 1). ${ }^{10}$ More importantly, it is reported that alcohol promotes

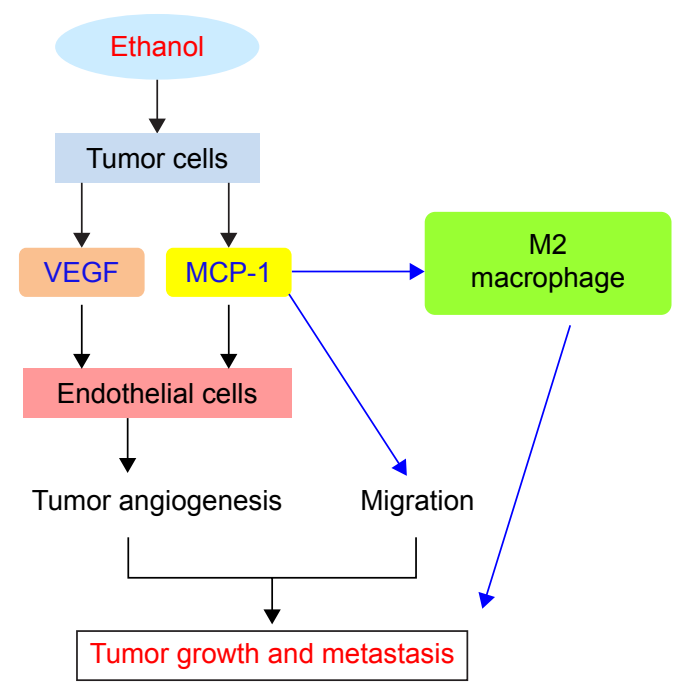

Figure I Role of VEGF and MCP-I in alcohol-induced tumor growth and metastasis.

Notes: Alcohol exposure upregulates VEGF level, thus promoting angiogenesis of endothelial cells. Alcohol exposure activates MCP-I and recruits M2 macrophages, which, in turn, promotes the growth and metastasis of cancer cells.

the growth and angiogenesis of breast cancer through activation of MCP-1 and its receptor CCR2 (Figure 1). ${ }^{11}$ Consistent with this idea, antagonists of CCR2 can inhibit tumor angiogenesis induced by alcohol. ${ }^{11}$ Alcohol can also promote the migration and invasion of colorectal cancer cells (CSCs) by regulating the $\mathrm{GSK} 3 \beta / \beta$-catenin/MCP-1 signaling pathway. ${ }^{12}$ However, the exact mechanisms of how MCP-1 mediated the effects, ie, alcohol stress-induced tumorigenesis and tumor growth, are still unclear.

\section{TLR}

TLR is a type I transmembrane receptor and pathogenic pattern recognition receptor, which participates in natural immunity. TLR plays an important role in cellular immune responses. ${ }^{37}$ Furthermore, some cytokines also regulate stem cells. For example, TLR induces NANOG gene expression, which is involved in the regulation of tumor-initiating stemlike cells (TICs). ${ }^{38}$

Recent studies found that TLR may play an important role in alcohol-induced liver cancer by regulating the $\mathrm{TICs},{ }^{38}$ at least partially through Nanog, one of the embryonic stem cell markers, which, in turn, regulates the proliferation and differentiation of liver stem/progenitor cells. ${ }^{39}$ Once activated, the proportion of CD133/Nanog-positive cells increased in liver cancer. ${ }^{40}$ Conversely, knocking off TLR genes can prevent tumor growth to a certain extent. ${ }^{41}$ Interestingly, studies found that ethanol-treated malignant cells fused to dendritic cells (DCs) exposed to TLR stimulation, thus promoting 
abnormal cellular immune response, which is thought to be an important mechanism of tumor promotion. ${ }^{42}$

Overall, these data suggested that chronic alcohol stress may play an important role in tumor promotion at least partially through the TLR/Nanog pathway.

\section{TNF- $\alpha$}

TNF- $\alpha$ is a type II membrane protein, which is mainly secreted by the activated mononuclear macrophages and could act either as a tumor suppressor or as an oncogene. TNF- $\alpha$ plays an antitumor role by inducing apoptosis, inhibiting tumor angiogenesis, and enhancing host immunity. ${ }^{43,44}$ TNF- $\alpha$ also acts as an oncogene by upregulating inflammatory cytokines, inhibiting apoptosis, and activating multiple signaling pathways, causing tumor-associated gene mutation. ${ }^{45,46}$ The increased TNF- $\alpha$ in tumor microenvironment can promote tumor cell migration and invasion, ${ }^{47}$ which is associated with metastasis, recurrence, and poor prognosis of cancer patients. ${ }^{48}$ More importantly, chronic ethanol exposure can upregulate TNF- $\alpha$, which, in turn, facilities infiltration of monocytes/macrophages in liver and, therefore, promotes liver lesions. For instance, TNF increased significantly in the liver tissue of alcohol-fed mice. ${ }^{49}$ However, the underlying mechanisms of TNF- $\alpha$ variation in alcohol-induced tumor promotion need to be further explored.

\section{Alcohol-induced dysregulation of transcription factors mediated by cytokines and chemokines}

Cytokines and chemokines directly or indirectly regulate transcription factors, which play key roles in integrating the multiple extracellular signaling pathways and regulating gene expression. The transcription factors known to be regulated by cytokines and chemokines include Egr-1, AP-1, and STAT.

Alcohol exposure affects the activity of transcription factors. Some of these transcription factors are known to be involved in the action of cytokines and chemokines as well as tumorigenesis/progression. ${ }^{50-53}$ In the present study, we focus on the three transcription factors that are affected by alcohol exposure, namely, Egr-1, STAT, and AP-1.

\section{Egr-I}

Egr-1 is a nuclear transcription factor that is regulated by the mitogen-activated protein kinase (MAPK) signaling pathway. ${ }^{54}$ Egr-1 binds to the promoter region of TNF- $\alpha$ and increases the sensitivity of liver macrophages. ${ }^{55}$ Egr-1 is upregulated in the process of alcoholic cirrhosis. ${ }^{50}$
Lipopolysaccharide (LPS)-induced activation of Egr-1 in the liver Kupffer cells contributes to the pathogenesis of alcoholic liver disease. ${ }^{51}$ In addition, chronic alcohol exposure also induces Egr-1 to bind to the promoter region of the TNF- $\alpha$ and increases the sensitivity of liver macrophages. ${ }^{55}$ Alcohol-induced liver cirrhosis may in the long run increase the risk of liver carcinogenesis.

Egr-1 also plays an important role in the process of tumorigenesis. ${ }^{56}$ Egr-1 has been found highly expressed in gastric cancer and bladder cancer, ${ }^{57,58}$ and it may upregulate invasion and metastasis-related genes, such as matrix metalloproteinases (MMP3). ${ }^{59}$ However, whether alcohol promotes tumor metastasis by activating Egr-1 is largely unknown.

\section{STAT}

The activity of STAT is regulated by JAK-mediated signal transduction, which can be activated by cytokines and chemokines. ${ }^{60}$ MAPK/STAT3 signaling pathway increases the DNA binding ability of AP-1 through the activation of Src kinases, thereby inducing the production of IL-10. ${ }^{61,62}$

During alcoholic liver injury, STAT3 modulates the liver immune response in a cell-type-dependent manner. For example, in liver cells, STAT3 exerts a pro-inflammatory role, whereas in mononuclear cells and Kupffer cells, STAT3 plays an anti-inflammatory role. ${ }^{52}$ In addition, the decreased liver regeneration capacity of patients with alcoholic cirrhosis is related to the decreased activity of STAT3, revealing a positive correlation between STAT3 and liver regeneration ability. ${ }^{53}$ Nevertheless, it is still unclear how ethanol exposure regulates STAT3 in liver cancer.

\section{AP-I}

AP-1 is a transcription factor that belongs to the leucine zipper protein family. ${ }^{63} \mathrm{AP}-1$ responds to cytokines by regulating the expression of a number of genes related to carcinogenesis and tumor progression. AP-1 and other transcription factors, including STAT3, SP-1, and SP-3, are all involved in LPS-induced production of IL-10 in monocytes and T cells. ${ }^{64-67}$ Meanwhile, it has been demonstrated that alcohol exposure activates the Src/MAPK/STAT3 signaling pathway and increases the DNA binding ability of AP-1, thereby inducing the production of IL- $10 .{ }^{61}$ In the context of liver injury, alcohol exposure enhances the sensitivity of liver macrophages via upregulating AP-1 and increasing the expression of CD14. ${ }^{68}$ Alcohol exposure can also activate AP-1 in a protein kinase C (PKC)-dependent manner and enhance proliferation ability of liver cells by increasing the expression of c-Jun and c-Fos in the liver cells. ${ }^{69}$ 
Alcohol-induced liver injury may also in the long run increase the risk of liver carcinogenesis.

\section{Alcohol-induced dysregulation of signaling pathways in the action of cytokines and chemokines}

There are a number of signaling pathways that are regulated by cytokines and chemokines and play an important role in tumorigenesis and progression. On the other hand, these signaling pathways can also modulate the expression of cytokines and chemokines. The most important signaling pathways involved in the action of cytokines and chemokines are NF- $\kappa \mathrm{B}-\mathrm{TNF}-\alpha$ signaling pathway, MAPK signaling pathway, and $\mathrm{Wnt} / \beta$-catenin signaling pathway.

Alcohol can cause the dysregulation of some signaling pathways that are involved in the action of cytokines, chemokines, tumorigenesis, and progression. In the present review, we discuss the three most important signaling pathways affected by alcohol exposure.

\section{NF- $\kappa$ B-TNF- $\alpha$ signaling pathway}

TNF- $\alpha$ is involved in multiple signaling pathways and can activate NF- $\kappa \mathrm{B}$ which, in turn, also participates in regulating TNF- $\alpha{ }^{70}$ LPS-induced oxidative stress activates NF- $\kappa \mathrm{B}$, increasing TNF- $\alpha$ production in Kupffer cells. LPS activates Kupffer cells and induces the production of superoxides that activate NF- $\kappa \mathrm{B}$. Once activated, NF- $\kappa \mathrm{B}$ is translocated to the nucleus and regulates the expression of several critical inflammatory cytokines, particularly TNF- $\alpha .{ }^{71}$ Blocking the activation of NF- $\kappa$ B markedly decreases cytokine production and ameliorates inflammation and necrosis. ${ }^{72}$ It has been reported that alcohol-induced liver damage is associated with the activation of the NF- $\kappa \mathrm{B}$ signaling pathway as well as the high expression of pro-inflammatory cytokines and upregulation of TLR3 and TLR7. ${ }^{73}$ It is believed that alcohol exposure regulates the inflammatory response of hepatic macrophages at least partially through the NF- $\kappa \mathrm{B}$ signaling pathway. Alcohol can activate the NF- $\kappa \mathrm{B}$ signaling pathway by affecting its nuclear localization, formation of NF- $\kappa \mathrm{B}$ p65/p50 dimmers, and DNA binding activity. ${ }^{71,73,74}$ In the mouse model of alcohol-induced liver injury, alcohol consumption causes a significant increase in DNA binding activity of NF- $\kappa \mathrm{B}$ in the liver. ${ }^{73}$

Our recent study demonstrated that alcohol exposure activates the NF- $\kappa \mathrm{B}$ signaling pathway and upregulates its target cytokines and chemokines, VEGF and MCP-1, which promote angiogenesis, growth, and metastasis of liver cancer cells. ${ }^{9}$

\section{MAPK signaling pathway}

MAPK signaling pathway is involved in mediating the tumorigenesis and metastasis. ${ }^{75}$ Cytokines and chemokines can activate three members of the MAPK family, namely, ERK1/2, p38 MAPK, and JNK/SAPK. ${ }^{76,77}$ Among them, the p38 MAPK pathway is required for the induction of TNF- $\alpha$ RNA-binding activity and mediates stabilization of TNF- $\alpha$ mRNA in myeloid cells stimulated with bacterial LPS. ${ }^{78}$ Alcohol affects the MAPK family and activates the three members of this family, namely ERK, p38 MAPK, and JNKs. A recent study showed that alcohol promotes malignant progression of breast cancer by activating the $\mathrm{p} 38 \gamma \mathrm{MAPK} /$ RhoC signaling pathway. ${ }^{79}$ Alcohol activates p38 MAPK in mononuclear cells, which generates anti-inflammatory cytokines such as IL-10 ${ }^{80}$ Similarly, it is reported that alcohol stimulates the liver macrophages to produce TNF- $\alpha$ through the activation of ERK1/2. ${ }^{81}$ Alcohol exposure also activates Src/MAPK/STAT3 and increases the binding ability of AP-1. ${ }^{61}$ Meanwhile, JNK was activated by alcohol in breast cancer cells and required for alcohol-induced cell invasion. ${ }^{82}$ Since MAPKs play an important role in tumorigenesis and progression, the effect of alcohol on MAPKs has a significant impact on tumor promotion.

\section{$\mathrm{Wnt} / \beta$-catenin signaling pathway}

$\mathrm{Wnt} / \beta$-catenin signaling pathway regulates tumor growth and metastasis ${ }^{83}$ as well as self-renewal and differentiation of cancer stem cells. ${ }^{84}$ Some cytokines are implicated in the regulation of $\mathrm{Wnt} / \beta$-catenin signaling. On the one hand cytokine such as TNF- $\alpha$ activates Wnt $\beta$-catenin signaling, on the other hand $\mathrm{Wnt} / \beta$-catenin signaling also affects specific cytokines. ${ }^{34,85,86}$ For example, IL- $1 \beta$ and TNF- $\alpha$ induced rat nucleus pulposus cells apoptosis by activating the caveolin- $1 / \mathrm{Wnt} / \beta$-catenin signaling pathway. ${ }^{85} \mathrm{TNF}-\alpha$ induced NF- $\kappa \mathrm{B}$ activation inhibits osteogenesis of mesenchymal stem cells by targeting $\mathrm{Wnt} / \beta$-catenin signaling. ${ }^{86}$ Furthermore, MCP-1 is a target of the $\beta$-catenin/TCF/LEF pathway in breast tumor cells and plays a key role in breast tumor progression. ${ }^{34}$

Recent studies demonstrated that alcohol activates the $\mathrm{Wnt} / \beta$-catenin signaling pathway and promotes malignant proliferation of cancer cells and tumor formation in the liver. ${ }^{87,88}$ Our previous study found that the $\mathrm{Wnt} / \beta$-catenin pathway mediates alcohol-stimulated MCP-1 gene transcription and enhances CSC metastasis. ${ }^{12}$ Whether the Wnt $/ \beta$ catenin signaling pathway is activated by alcohol stress in other tumors, such as breast cancer, colon cancer, and the underlying molecular mechanisms are undiscovered. 


\section{Cytokines and chemokines as potential therapeutic targets}

Cytokines and chemokines are potential therapeutic targets for the treatment of alcohol-induced tumor promotion as well as other alcohol-related diseases. They may be used as biomarkers for alcohol-induced organ damage. For example, MCP-1 levels in cerebrospinal fluid, together with gamma glutamyltransferase (GGT) and aspartate aminotransferase/glutamic oxaloacetic transaminase (AST/GOT) in peripheral blood, are indicators of clinical alcoholic hepatitis in alcoholics. ${ }^{89}$ Recent studies showed that blocking NF- $\kappa$ B-regulated MCP-1 and VEGF expression inhibits alcohol-induced tumor formation ability of liver cancer cells. ${ }^{9}$ Similarly, blocking Wnt $\beta$-catenin signaling inhibits alcohol-stimulated MCP-1 expression and alleviates alcoholinduced invasion of colon cancer cells. ${ }^{12}$ These studies suggest that targeting cytokines and chemokines may be a potential therapeutic strategy for cancer treatment, particularly in the context of alcohol-induced tumor promotion.

\section{Conclusion}

- Excessive alcohol consumption is a risk factor for cancer. Alcohol promotes tumorigenesis, progression, and metastasis.

- Alcohol causes dysregulation of cytokines and chemokines, which may mediate alcohol-induced tumor promotion. Alcohol may also affect transcription factors and signaling pathways that regulate the expression/function of cytokines and chemokines.

- Systematic screening of cytokines and chemokines that are affected by alcohol during tumorigenesis and cancer progression is necessary for providing more insight into the role of cytokines and chemokines in alcohol-induced tumor promotion. Targeting cytokines and chemokines could be a potential therapeutic strategy for cancer treatment, particularly in the context of alcohol-induced tumor promotion/progression.

\section{Acknowledgment}

This work was supported by the Project of the National Natural Sciences Foundation of China (81272258, 81572749).

\section{Disclosure}

The authors report no conflicts of interest in this work.

\section{References}

1. Pöschl G, Stickel F, Wang XD, Seitz HK. Alcohol and cancer: genetic and nutritional aspects. Proc Nutr Soc. 2004;63(1):65-71.
2. Scoccianti C, Cecchini M, Anderson AS, et al. European code against cancer 4th edition: alcohol drinking and cancer. Cancer Epidemio. 2015; 39(suppl 1):S67-S74.

3. Pöschl G, Seitz HK. Alcohol and cancer. Alcohol Alcohol. 2004;39(3): 155-165.

4. Baan R, Straif K, Grosse Y, et al; WHO International Agency for Research on Cancer Monograph Working Group. Carcinogenicity of alcoholic beverages. Lancet Oncol. 2007;8(4):292-293.

5. Rehm J, Baliunas D, Borges GL, et al. The relation between different dimensions of alcohol consumption and burden of disease: an overview. Addiction. 2010;105(5):817-843.

6. Suzuki R, Ye W, Rylander-Rudqvist T, Saji S, Colditz GA, Wolk A. Alcohol and postmenopausal breast cancer risk defined by estrogen and progesterone receptor status: a prospective cohort study. J Natl Cancer Inst. 2005;97(21):1601-1608.

7. Orywal K, Szmitkowski M. Alcohol dehydrogenase and aldehyde dehydrogenase in malignant neoplasms. Clin Exp Med. Epub 2016 Feb 17

8. Tan W, Bailey AP, Shparago M, et al. Chronic alcohol consumption stimulates VEGF expression, tumor angiogenesis and progression of melanoma in mice. Cancer Biol Ther. 2007;6(8):1211-1217.

9. Wang F, Yang JL, Yu KK, et al. Activation of the NF- $\kappa$ B pathway as a mechanism of alcohol enhanced progression and metastasis of human hepatocellular carcinoma. Mol Cancer. 2015;14:10.

10. Yu K, Yang J, Wang F, et al. Alcohol supports macrophage recruitment and reinforces invasion and migration of lewis lung carcinoma. Alcohol Clin Exp Res. 2014;38(10):2597-2606.

11. Wang $\mathrm{S}, \mathrm{Xu} \mathrm{M}, \mathrm{Li} \mathrm{F}$, et al. Alcohol promotes mammary tumor growth and angiogenesis: the involvement of chemoattractant factor MCP-1. Breast Cancer Res Treat. 2012;133(3):1037-1048.

12. Xu M, Wang S, Qi Y, et al. Role of MCP-1 in alcohol-induced aggressiveness of colorectal cancer cells. Mol Carcinog. 2016;55(5): 1002-1011.

13. Im HJ, Kim HG, Lee JS, et al. A preclinical model of chronic alcohol consumption reveals increased metastatic seeding of colon cancer cells in the liver. Cancer Res. 2016;76(7):1698-1704.

14. Licaj I, Sandin S, Skeie G, et al. Alcohol consumption over time and mortality in the Swedish Women's Lifestyle and Health cohort. BMJ Open. 2016;6(11):e012862.

15. Ramji DP, Davies TS. Cytokines in atherosclerosis: key players in all stages of disease and promising therapeutic targets. Cytokine Growth Factor Rev. 2015;26(6):673-685.

16. Moss JW, Ramji DP. Cytokines: roles in atherosclerosis disease progression and potential therapeutic targets. Future Med Chem. 2016; 8(11):1317-1330.

17. Van der Vorst EP, Döring Y, Weber C. Chemokines. Arterioscler Thromb Vasc Biol. 2015;35(11):52-56.

18. Arya M, Patel HR, Williamson M. Chemokines: key players in cancer. Curr Med Res Opin. 2003;19(6):557-564.

19. Balkwill F. Chemokine biology in cancer. Semin Immunol. 2003;15(1) 49-55.

20. Daniluk J, Kandefer-Szerszeń M. The effect of alcohol on the immune system and cytokines. Postepy Hig Med Dosw. 1998;52(1):49-65.

21. Kawaratani H, Tsujimoto T, Douhara A, et al. The effect of inflammatory cytokines in alcoholic liver disease. Mediators Inflamm. 2013; 2013:495156.

22. An L, Wang X, Cederbaum AI. Cytokines in alcoholic liver disease. Arch Toxicol. 2012;86(9):1337-1348.

23. Tischer E, Mitchell R, Hartman T, et al. The human gene for vascular endothelial growth factor, multiple protein forms are encoded through alternative exon splicing. J Biol Chem. 1991;266(18): 11947-11954.

24. Ferrara $\mathrm{N}$. Vascular endothelial growth factor: molecular and biological aspects. Curr Top Microbiol Immunol. 1999;237:1-30.

25. Yancopoulos GD, Davis S, Gale NW, Rudge JS, Wiegand SJ, Holash J. Vascular-specific growth factors and blood vessel formation. Nature. 2000;407(6801):242-248. 
26. Tsai MS, Chang CC, Kuo ML, Wu YT. Vascular endothelial growth factor-A and changes in a tumor-bearing mouse model with Lewis lung cancer. Oncol Lett. 2011;2(6):1143-1147.

27. Claesson-Welsh L, Welsh M. VEGFA and tumour angiogenesis. J Intern Med. 2013;273(2):114-127.

28. Ferrara N, Gerber HP, LeCouter J. The biology of VEGF and its receptors. Nat Med. 2003;9(6):669-676.

29. Hicklin DJ, Ellis LM. Role of the vascular endothelial growth factor pathway in tumor growth and angiogenesis. J Clin Oncol. 2005;23(5): 1011-1027.

30. El-Assal ON, Yamanoi A, Soda Y, et al. Clinical significance of microvessel density and vascular endothelial growth factor expression in hepatocellular carcinoma and surrounding liver: possible involvement of vascular endothelial growth factor in the angiogenesis of cirrhotic liver. Hepatology. 1998;27(6):1554-1562.

31. Mise M, Arii S, Higashituji H, et al. Clinical significance of vascular endothelial growth factor gene expression in liver tumor. Hepatology. 1996;5:455-464.

32. Lu Y, Ni F, Xu M, et al. Alcohol promotes mammary tumor growth through activation of VEGF-dependent tumor angiogenesis. Oncol Lett. 2014;8(2):673-678.

33. McClellan JL, Davis JM, Steiner JL, et al. Linking tumor-associated macrophages, inflammation, and intestinal tumorigenesis: role of MCP-1. Am J Physiol Gastrointest Liver Physiol. 2012;303(10):1087-1095.

34. Mestdagt M, Polette M, Buttice G, et al. Transactivation of MCP-1/ CCL 2 by $\beta$-catenin/TCF- 4 in human breast cancer cells. Int $J$ Cancer. 2006;118(1):35-42.

35. Yoshidome H, Kohno H, Shida T, et al. Significance of monocyte chemoattractant protein-1 in angiogenesis and survival in colorectal liver metastases. Int J Oncol. 2009;34(4):923-930.

36. Armaiz-Pena GN, Gonzalez-Villasana V, Nagaraja AS, et al. Adrenergic regulation of monocyte chemotactic protein 1 leads to enhanced macrophage recruitment and ovarian carcinoma growth. Oncotarget. 2015;6(6):4266-4273.

37. Matsuoka Y, Takagi H, Yamatani M, Kuroda Y, Sato K, Kojima N. Requirement of TLR4 signaling for the induction of a Th1 immune response elicited by oligomannose-coated liposomes. Immunol Lett. 2016;16:30131-30136.

38. Machida K, Feldman DE, Tsukamoto H. TLR4-dependent tumorinitiating stem cell-like cells (TICs) in alcohol-associated hepatocellular carcinogenesis. Adv Exp Med Biol. 2015;815:131-144.

39. Machida K, Tsukamoto H, Mkrtchyan H, et al. Toll-like receptor 4 mediates synergism between alcohol and $\mathrm{HCV}$ in hepatic oncogenesis involving stem cell marker Nanog. Proc Natl Acad Sci U S A. 2009;106(5):1548-1553.

40. Machida K. TLRs, alcohol, HCV, and tumorigenesis. Gastroenterol Res Pract. 2010;2010:518674.

41. French SW, Oliva J, French BA, Li J, Bardag-Gorce F. Alcohol, nutrition and liver cancer: role of Toll-like receptor signaling. World $J$ Gastroenterol. 2010;16(11):1344-1348.

42. Koido S, Homma S, Okamoto M, et al. Improved immunogenicity of fusions between ethanol-treated cancer cells and dendritic cells exposed to dual TLR stimulation. Oncoimmunology. 2013;2(8):e25375.

43. Koss M, Pfeiffer GR, Wang Y, et al. Ezrin/radixin/moesin proteins are phosphorylated by TNF- $\alpha$ and modulate permeability increases in human pulmonary microvascular endothelial cells. J Immunol. 2006; 176(2):1218-1227.

44. Zhang W, Chen Z, Li F, et al. Tumour necrosis factor-alpha (TNF-alpha) transgene-expressing dendritic cells (DCs) undergo augmented cellular maturation and induce more robust $\mathrm{T}$-cell activation and anti-tumour immunity than DCs generated in recombinant TNF-alpha. Immunology. 2003;108(2):177-188.

45. Akiyama M, Hideshima T, Hayashi T, et al. Nuclear factor-kappaB p65 mediates tumor necrosis factor alpha-induced nuclear translocation of telomerase reverse transcriptase protein. Cancer Res. 2003;63(1): $18-21$.
46. Soria G, Ofri-Shahak M, Haas I, et al. Inflammatory mediators in breast cancer: coordinated expression of TNF- $\alpha \&$ IL- $\beta$ with CCL2 \& CCL5 and effects on epithelial-to-mesenchymal transition. BMC Cancer. 2011; 11:1471-1491.

47. Radhakrishnan P, Chachadi V, Lin MF, Singh R, Kannagi R, Cheng PW. $\mathrm{TNF} \alpha$ enhances the motility and invasiveness of prostatic cancer cells by stimulating the expression of selective glycosyl and sulfotransferase genes involved in the synthesis of selectin ligands. Biochem Biophys Res Commun. 2011;409(3):436-441.

48. Ferrajoli A, Keating MJ, Manshouri T, et al. The clinical significance of tumor necrosis factor- $\alpha$ plasma level in patients having chronic lymphocytic leukemia. Blood. 2002;100(4):1215-1219.

49. Olleros ML, Martin ML, Vesin D, et al. Fat diet and alcohol-induced steatohepatitis after LPS challenge in mice: role of bioactive TNF and Th1 type cytokines. Cytokine. 2008;44(1):118-125.

50. Donohue TM Jr, Osna NA, Trambly CS, et al. Early growth response-1 contributes to steatosis development after acute ethanol administration. Alcohol Clin Exp Res. 2012;36(5):759-767.

51. Kishore R, Hill JR, McMullen MR, Frenkel J, Nagy LE. ERK1/2 and Egr-1 contribute to increased TNF- $\alpha$ production in rat Kupffer cells after chronic alcohol feeding. Am J Physiol Gastrointest Liver Physiol. 2002;282(1):G6-G15

52. Horiguchi N, Wang L, Mukhopadhyay P, et al. Cell type-dependent pro- and anti-inflammatory role of signal transducer and activator of transcription 3 in alcoholic liver injury. Gastroenterology. 2008;134(4): $1148-1158$.

53. Chen J, Bao H, Sawyer S, Kunos G, Gao B. Effects of short and long term ethanol on the activation of signal transducer and activator transcription factor 3 in normal and regenerating liver. Biochem Biophys Res Commun. 1997;239(3):666-669.

54. Gashler A, Sukhatme VP. Early growth response protein 1 (Egr-1) prototype of a zinc-finger family of transcription factors. Prog Nucleic Acid Res Mol Biol. 1995;50:191-224.

55. Pritchard MT, Nagy LE. Alcohol-induced liver injury: potential roles for egr-1. Alcohol Clin Exp Res. 2005;29(11 suppl):146S-150S.

56. Mitchell A, Crispin R, dass L, et al. The neuroplasticity-associated gene is a direct transcriptional target of early growth response (Egr) transcription factors. Mol Cell Biol. 2005;25:1028-10300.

57. Kobayashi D, Yamada M, Kamagata C, et al. Overexpression of early growth response-1 as a metastasis-regulatory factor in gastric cancer. Anticancer Res. 2002;22(6C):3963-3970.

58. Egerod FL, Nielsen HS, Iversen L, Thorup I, Storgaard T, Oleksiewicz MB. Biomarkers for early effects of carcinogenic dual-acting PPAR agonists in rat urinary bladder urothelium in vivo. Biomarkers. 2005; 10(4):295-309.

59. Kato N, Kobayashi T, Honda H. Screening of stress enhancer based on analysis of gene expression profiles: enhancement of hyperthermiainduced tumor necrosis by an MMP-3 inhibitor. Cancer Sci. 2003;94(7): 644-649.

60. Kisseleva T, Bhattacharya S, Braunstein J, Schindler CW. Signaling through the JAK/STAT pathway, recent advances and future challenges. Gene. 2002;285(1-2):1-24.

61. Norkina O, Dolganiuc A, Shapiro T, Kodys K, Mandrekar P, Szabo G. Acute alcohol activates STAT3, AP-1, and Sp-1 transcription factors via the family of Src kinases to promote IL-10 production in human monocytes. J Leukoc Biol. 2007;82(3):752-762.

62. Norkina O, Dolganiuc A, Catalano D, et al. Acute alcohol intake induces SOCS1 and SOCS3 and inhibits cytokine-induced STAT1 and STAT3 signaling in human monocytes. Alcohol Clin Exp Res. 2008; 32(9):1565-1573.

63. Angel P, Karin M. The role of Jun, Fos and the AP-1 complex in cell proliferation and transformation. Biochem Biophys Acta. 1991; 1072(2-3):129-157.

64. Wang ZY, Sato H, Kusam S, Sehra S, Toney I, Dent A. Regulation of IL-10 gene expression in Th2 cells by Jun proteins. J Immunol. 2005; 174(4):2098-2105. 
65. Ma W, Lim W, Gee K, et al. The p38 mitogen-activated kinase pathway regulates the human interleukin-10 promoter via the activation of Sp1 transcription factor in lipopolysaccharide-stimulated human macrophages. J Biol Chem. 2001;276(17):13664-13674.

66. Tone M, Powell M, Tone Y, Thompson S, Waldmann H. IL-10 gene expression is controlled by the transcription factors Sp1 and Sp3. J Immunol. 2000;165(1):286-291.

67. Benkhart EM, Siedlar M, Wedel A, Werner T, Ziegler-Heitbrock H. Role of Stat3 in lipopolysaccharide-induced IL-10 gene expression. J Immunol. 2000;165(3):1612-1617.

68. Wheeler MD, Thurman RG. Upregulation of CD14 in liver due to acute alcohol involves oxidant-dependent AP-1 pathway. J Biol Chem. 2003;278(10):8345-8351.

69. Casini A, Galli G, Salzano R, et al. Acetaldehyde induces c-Fos and c-Jun proto-oncogenes in fat-storing cell cultures through protein kinase C activation. Alcohol Alcohol. 1994;29(3):303-314.

70. Dempsey PW, Doyle SE, He JQ, Cheng G. The signaling adaptors and pathways activated by TNF superfamily. Cytokine Growth Factor Rev. 2003;14(3-4):193-209.

71. Wheeler MD, Yamashina S, Froh M, Rusyn I, Thurman RG. Adenoviral gene delivery can inactivate Kupffer cells: role of oxidants in NF-kappaB activation and cytokine production. J Leukoc Biol. 2001;69(4): 622-630.

72. Nanji AA, Jokelainen K, Rahemtulla A, et al. Activation of nuclear factor kappa B and cytokine imbalance in experimental alcoholic liver disease in the rat. Hepatology. 1999;30(4):934-943.

73. Stärkel P, De Saeger C, Strain AJ, Leclercq I, Horsmans Y. NFkappaB, cytokines, TLR 3 and 7 expression in human end-stage HCV and alcoholic liver disease. Eur J Clin Invest. 2010;40(7):575-584.

74. Szabo G, Mandrekar P. Alcohol-mediated regulation of transcription factors in immunocompetent cells. Front Biosci. 2002;7:80-89.

75. Liu YW, Zuo PY, Zha XN, et al. Octacosanol enhances the proliferation and migration of human umbilical vein endothelial cells via activation of the PI3K/Akt and MAPK/Erk pathways. Lipids. 2015;50(3):241-251.

76. Petecchia L, Sabatini F, Usai C, Caci E, Varesio L, Rossi GA. Cytokines induce tight junction disassembly in airway cells via an EGFR-dependent MAPK/ERK1/2-pathway. Lab Invest. 2012;92(8):1140-1148.

77. Korobowicz A. Biology of tumor necrosis factor type alpha (TNFalpha). Pol Merkur Lekarski. 2006;21(124):358-361.

78. Mahtani KR, Brook M, Dean JL, Sully G, Saklatvala J, Clark AR. Mitogen-activated protein kinase p38 controls the expression and posttranslational modification of tristetraprolin, a regulator of tumor necrosis factor alpha mRNA stability. Mol Cell Biol. 2001;21(19): 6461-6469.
79. Xu M, Wang S, Ren Z, et al. Chronic alcohol exposure enhances the aggressiveness of breast cancer: the role of p38 $\gamma$. Oncotarget. 2016; 7(3):3489-3505.

80. Drechsler Y, Dolganiuc A, Norkina O, et al. Heme oxygenase-1 mediates the anti-inflammatory effects of acute alcohol on IL-10 induction involving p38MAPK activation in monocytes. J Immunol. 2006; 177(4):2592-2600.

81. Agoglia AE, Sharko AC, Psilos KE, Holstein SE, Reid GT, Hodge CW. Alcohol alters the activation of ERK1/2, a functional regulator of binge alcohol drinking in adult C57BL/6J mice. Alcohol Clin Exp Res. 2015;39(3):463-475.

82. Ma C, Lin H, Leonard SS, Shi X, Ye J, Luo J. Overexpression of erbb2 enhances ethanol-stimulated intracellular signaling and invasion of human mammary epithelial and breast cancer cells in vitro. Oncogene. 2003;22(34):5281-5290.

83. Rattis FM, Voermans C, Reya T. Wnt signaling in the stem cell niche. Curr Opin Hematol. 2004;11(2):88-94.

84. Miki T, Yasuda SY, Kahn M. Wnt/ $\beta$-catenin signaling in embryonic stem cell self-renewal and somatic cell reprogramming. Stem Cell Rev. 2011;7(4):836-846.

85. Wang J, Chen $\mathrm{H}, \mathrm{Cao} \mathrm{P}$, et al. Inflammatory cytokines induce caveolin$1 / \beta$-catenin signalling in rat nucleus pulposus cell apoptosis through the p38 MAPK pathway. Cell Prolif. 2016;49(3):362-372.

86. Wang $\mathrm{N}$, Zhou $\mathrm{Z}, \mathrm{Wu} \mathrm{T}$, et al. TNF- $\alpha$-induced NF- $\kappa \mathrm{B}$ activation upregulates microRNA-150-3p and inhibits osteogenesis of mesenchymal stem cells by targeting $\beta$-catenin. Open Biol. 2016;6(3):150258.

87. Mercer KE, Hennings L, Sharma N, et al. Alcohol consumption promotes diethylnitrosamine-induced hepatocarcinogenesis in male mice through activation of the Wnt $\beta$-catenin signaling pathway. Cancer Prev Res (Phila). 2014;7(7):675-685.

88. Mercer KE, Hennings L, Ronis MJ. Alcohol consumption, Wnt/ $\beta$ catenin signaling, and hepatocarcinogenesis. Adv Exp Med Biol. 2015; 815:185-195.

89. Umhau JC, Schwandt M, Solomon MG, et al. Cerebrospinal fluid monocyte chemoattractant protein-1 in alcoholics: support for a neuroinflammatory model of chronic alcoholism. Alcohol Clin Exp Res. 2014;38(5) 1301-1306.
OncoTargets and Therapy

\section{Publish your work in this journal}

OncoTargets and Therapy is an international, peer-reviewed, open access journal focusing on the pathological basis of all cancers, potential targets for therapy and treatment protocols employed to improve the management of cancer patients. The journal also focuses on the impact of management programs and new therapeutic agents and protocols on

\section{Dovepress}

patient perspectives such as quality of life, adherence and satisfaction. The manuscript management system is completely online and includes a very quick and fair peer-review system, which is all easy to use. Visit http://www.dovepress.com/testimonials.php to read real quotes from published authors. 